TITLE PAGE

Type of Article: Review Article

\title{
Measuring the dengue risk area using Geographic Information System: a review
}

\author{
Raodatul Zannah ${ }^{1}$, Sulistyawati Sulistyawati ${ }^{1}{ }^{*}$, Ineu Fitria Dewi ${ }^{1}$ \\ ${ }^{1}$ Faculty of Public Health, University of Ahmad Dahlan, Yogyakarta, Indonesia
}

* Corresponding author:

\section{Sulistyawati}

Department of Public Health,

Ahmad Dahlan University,

Yogyakarta, Indonesia

Phone (or Mobile) No .: +6281 70402693

E-mail: sulistyawatisuyanto@gmail.com 


\begin{abstract}
Background: Dengue is a viral infection transmitted by mosquitoes that continue to be a significant health challenge in many tropical and subtropical countries. So far, Geographic Information System (GIS) in the health sector contributed to disease prevention, especially for visualization of the disease case. GIS is one of the important tools in spatial epidemiology to assist identification and spatial analysis of the target disease intervention. This article summarizes the use of GIS to assess risk factors for DHF, and how efficient the use of GIS in facilitating the improvement of disease surveillance systems for the prevention and control of diseases.
\end{abstract}

Methods: This paper was developed using a descriptive approach, conducted in September and December 2019. The primary data used in this research were from ScienceDirect databased by collecting some studies that assess the risk of dengue using GIS applications.

Results: The results of reviews of research in several countries which use GIS applications in assessing the risk of dengue incidence, ie, in Swat, Pakistan evaluated the impact of the slope, population density, and the distance to the river through GIS applications. Then in Seremban and Putrajaya, Malaysia implemented a participatory approach to identify the spatial risk of dengue in the community. Research in Lahore, Pakistan, analyzed the risk of dengue. Study in Colombia conducted GWR to evaluate the association between socioeconomic factors and the environment with dengue fever incidence. Recently, research in Taiwan integrated GIS to detect the correlation between population density and the possibility of human contact with mosquitoes.

Conclusions: Based on the results of the review, it can be drawn that asses the dengue risk with GIS applications is highly relevant because it can determine the factors which affect the incidence of dengue. Besides, it can determine the spatial correlation between risk factors and the incidence of dengue, as well as to evaluate the impact of the dengue occurrence.

Keywords: Assessment, Dengue Risk, GIS. 


\section{INTRODUCTION}

Dengue is a disease caused by dengue virus (DENV), which has occurred in more than 128 countries worldwide, with 4 billion people at risk of dengue virus infection ${ }^{1}$. Countries located in tropical and subtropical regions are particularly vulnerable to dengue. Many factors areaffecting the fast spread of dengue to other things such as environment and socioeconomic ${ }^{2}$.

Dengue hemorrhagic fever is now one of the most critical public health issues in tropical developing countries contributing to substantial economic and social consequences ${ }^{3}$. Dengue is a viral infection transmitted by mosquitoes, which continues to be a significant health challenge in many tropical and subtropical regions ${ }^{4}$. According to the World Health Organization (WHO), Aedes aegypti is the leading cause of dengue transmission. Dengue can not be transmitted directly from one to another; however, it is transferred by the Aedes mosquito infected person and suffering from Dengue fever. In India, dengue fever first appeared in Madras (now known as Chennai) during 1780. The recent dengue epidemics virologically have proven first occurred in Calcutta (now known as Kolkata) and the East Coast of India during 1963-19645

To date, the use of GIS in health provides much assist primarily in visualizing the case. It is one of the essential tools in spatial epidemiology to support the identification and spatial analysis of the target disease intervention ${ }^{1}$. The development of technology facilitates the prevention and control of diseases. GIS is an application which can be used to analyze the risk factors for DHF. Since dengue fever is an infectious disease which requires regular monitoring of its progress, GIS can be used to establish mapping to a disease so that the trend of events is visible.

The implementation of Geographic Information Systems in Environmental Impact Assessment (EIA) and public health have become popularly widespread. Recently, GIS is implemented in assessing vector-borne diseases such as site assessments vectors, vector assessment and monitoring, identification of the location of breeding, destruction of breeding locations, and other related fields. The ability of GIS indirect analysis, spatial analysis, and spatial statistics help obtain spatial correlation, and consequences are complex. GIS also performs complex mathematical operations and arithmetic calculations and displays realtime results. Furthermore, AHP, integrated with GIS modeling and mapping of dengue risk zoning, can display construction results with spatial correlation ${ }^{6}$.

The implementation of spatial analysis in geographic information systems (GIS) for medical purposes is one of the main techniques for identifying the spatial association, and it has been adopted by several researchers around the world ${ }^{7,8,9}$. The integration of AHP (Analytical Hierarchy Process) in a GIS to solve spatial planning problems has gained significant attention among multidisciplinary planners. The ability of GIS to integrate with the AHP has been demonstrated in several studies related to nature and environmental management ${ }^{10,11}$.

\section{METHODS}

This study was a descriptive review conducted between September to December 2019. ScienceDirect database was selected to collect research papers by keywords: "Asses of dengue risk using GIS." Firstly, researchers searched papers with the title of GIS. Paper that used GIS 
was included in the next phase. Secondly, the abstracts were evaluated to see the topics' appropriates: research on dengue and using GIS to assess the risk area. The paper which met the criteria of the topic would include in further analysis.

Papers were randomly selected based on the country to obtain the variation across the regions. Accordingly, we synthesized the included paper through the question: What method is used to assess dengue risk on the associated area?

\section{RESULTS}

There were 376 papers collected from the search process. Among which, xxx exclude paper was based on their abstract, and five papers were included in the analysis. Table 1 illustrates the paper included in the analysis.

\begin{tabular}{|c|c|c|}
\hline No. & title & method \\
\hline 1 & $\begin{array}{l}\text { Investigating Spatio-Temporal } \\
\text { Distribution and Diffusion } \\
\text { Patterns of the Dengue } \\
\text { Outbreak in Swat, Pakistan }{ }^{1}\end{array}$ & $\begin{array}{l}\text { Dengue cases from the hospital were visualized } \\
\text { into distribution and diffusion maps. Space-time } \\
\text { was used to calculate the spatiotemporal cluster, } \\
\text { and weighted regression analysis was calculated } \\
\text { to evaluate the impact of slop, population density, } \\
\text { and distance to the river. }\end{array}$ \\
\hline 2 & $\begin{array}{l}\text { Mosquitoes and Vulnerable } \\
\text { Spaces: Mapping Local } \\
\text { Knowledge of Sites for Dengue } \\
\text { Control in Seremban and } \\
\text { Putrajaya Malaysia }^{4}\end{array}$ & $\begin{array}{l}\text { The participative approach was used to identify } \\
\text { dengue spatial risk. Subjects consisted of two } \\
\text { groups: urban and } \\
\text { This study uses a participatory approach to } \\
\text { identify the risk of dengue spatial community. } \\
\text { Subjects were divided into two groups of an urban } \\
\text { area which was an area of the high risk of dengue } \\
\text { fever, the subjects were asked to describe their } \\
\text { area associated with equity mosquito which } \\
\text { further results into a GIS digitation sketch to } \\
\text { create a community of knowledge map. }\end{array}$ \\
\hline 3 & $\begin{array}{l}\text { Spatial Mapping of Temporal } \\
\text { Risk to Improve Prevention } \\
\text { Measures: A Case Study of } \\
\text { Dengue Epidemic in Lahore }{ }^{12} \text {, } \\
\text { Pakistan }\end{array}$ & $\begin{array}{l}\text { This research detected dynamic temporal-spatial } \\
\text { autocorrelation by using the Local Index of } \\
\text { Spatial Autocorrelation (LISA). Overlaid for each } \\
\text { temporal index produced risk analysis }\end{array}$ \\
\hline 4 & $\begin{array}{l}\text { A spatial model of } \\
\text { Socioeconomic and } \\
\text { environmental determinants of } \\
\text { dengue fever in Cali, } \\
\text { Colombia }^{2}\end{array}$ & $\begin{array}{l}\text { Geographically Weighted Regression models } \\
\text { were used to evaluate the relationship between } \\
\text { Socioeconomic and environmental factors and } \\
\text { dengue incidence }\end{array}$ \\
\hline 5 & $\begin{array}{l}\text { Incorporating the Human } \\
\text { Aedes Mosquito Spatial } \\
\text { Interactions Into Measuring the } \\
\text { Risk of Urban Dengue Fever } \\
{ }^{13} \text {, Taiwan }\end{array}$ & $\begin{array}{l}\text { This research integrated GIS to detect the } \\
\text { relationship between population density and } \\
\text { ovitrap and the possibility of contact between } \\
\text { human and mosquito }\end{array}$ \\
\hline
\end{tabular}

\section{DISCUSSION}


Mapping tools were more and more utilized for disease surveillance, vector control, and health promotion activities. Specifically, GIS had been introduced in operational control programs for malaria and supervision time against the West Nile virus. According to Zeller and Schuffenecker (2004), the West Nile virus was a flavivirus transmitted by the Culex mosquito species and transmitted from mosquito to bird. Some of the dengue control programs had been using GIS to monitor the daily mosquito surveillance data ${ }^{4}$. Results of other studies of dengue risk assessment using GIS conducted in Malaysia illustrated that GIS and spatial analysis methods could be applied to create control strategies dengue and other infectious diseases to control precautions ${ }^{15}$. Another study conducted in Thailand also stated that GIS application was one of the effective tools to control dengue. Where the results obtained from the three districts studied, Muang Samut Songkhram district was the only area which was at very high risk which covered $79.78 \mathrm{~km} 2$ and at the district level were areas of high risk and Lat Mae Khlong Yai ${ }^{16}$,

GIS applications in the medical world contributed vast assistants, especially in the case visualization, since it was one of the important tools in spatial epidemiology to assist the identification and spatial analysis of the target disease intervention ${ }^{4}$. In the analysis of risk factors by the necessary GIS data completeness, data collected were usually derived from secondary data obtained from a particular agency.The completeness of the data will support the analysis process and describe the actual conditions. A research conducted in Pakistan used to demonstrate the use of GIS spatiotemporal clusters against dengue outbreak, eventually bringing the study to the conclusion that the causes of the dengue incidence were caused by environmental factors ${ }^{1}$,

Another study carried out in India showed that GIS applications could detect dengue fever risk areas by integrating stagnant environmental parameters. The most affecting factors to dengue incidence were the density of homes, water area, land surface temperature, population density, land elevation, and land cover use. The results showed that the spatial correlation could help understand the distribution pattern of dengue fever and zoning potential risk areas ${ }^{6}$,

The application of GIS to assess the factors which affected the incidence of dengue in Thailand presented that four main factors out of 11 factors examined affected the incidence of dengue: population density, number of households, residential areas and human-made water resources ${ }^{16}$. Another similar study conducted in Malaysia was also stated that the factors most affected on dengue incidence were the housing type, population density, land use, and elevation ${ }^{15}$,

Dengue risk factor assessment was also conducted through GWR (Geographically Weighted Regression) assisted with spatial methods. It was implemented to look at the socioeconomic and environmental factors associated with dengue fever, which occurred in Cali, Colombia, in 2010. Social factors were the density of major economic population and socio-economic level. In contrast, the environmental factors were the proximity to the tire shop and nursery crops and where the sewage system $(\mathrm{R} 2=0.64)$. The strong correlation between these factors and the incidence of dengue fever was a spatially heterogeneous environment level. These findings supported public health strategies for allocating resources locally, which would allow better detection of high-risk areas, ${ }^{2}$,

Some of the views mentioned that dengue was caused by several factors. First, appropriate physical and social environment to the development of dengue vectors was considered highrisk areas of dengue fever. It illustrated that environmental conditions had a significant effect on the incidence of dengue. The second factor mentioned that dengue was caused by vector 
density monitoring through entomological surveys. Some studies suggested that many dengue indicated the number of dengue infections resulted from the vector density. It was recognized through mapping and analysis of the spatial distribution of mosquito. The approach described above was used to predict the dengue risk areas, but the information was not sufficient enough to explain human contact with mosquitoes. For transmission of dengue containing infectious DB mute and distribution of cases could not comprehensively reflect the risk of transmission. Human behavior was an important factor in measuring human contact with mosquitoes, and therefore exposure to the risk of dengueresulted from complex interactions between vectors and population ${ }^{13}$,

The population density was often used in epidemiological studies as a major factor in explaining the concept of risk populations. Data sources of these indicators were derived from surveys or demographic censuses based on residence location. The population density was used to measure the spatial risk of dengue transmission ${ }^{13}$, Geostatistical modeling to identify areas of disease risk factors. To measure the risk of an epidemic was an annual disease rate. The frequency of occurrence of the epidemic may vary in geographical space; thus, it required the spread temporal pattern of the epidemic. Therefore, the temporal pattern was very significant, the risk of the epidemic was more effectively in decision-making when analyzed temporal and spatial $^{12}$,

GIS-based maps to provide relevant information to assess the risks for individuals traveling to specific destinations in the epidemic-endemic area, which allowed the need for prevention. The map can be used to make prevention and control strategies, and other public health policy, to control vector-borne disease dengue ${ }^{17}$.

\section{Declarations}

Funding: There is no external funding for this research

Conflict of interest: Author (s) declare, there is no conflict of interest

Ethical approval: Not applicable

\section{REFERENCES}

1. Atique S, Chan T, Chen C, Hsu C, Iqtidar S, Louis VR, et al. Investigating spatiotemporal distribution and diffusion patterns of the dengue outbreak in Swat, Pakistan. J Infect Public Health. 2018; 11 (4): 550-7.

2. Delmelle E, Hagenlocher M, Kienberger S, Casas I. A spatial models of Socioeconomic and environmental determinants of dengue fever in Cali, Colombia. Acta Trop [Internet]. 2016; 164: 169-76. Available from: http://dx.doi.org/10.1016/j.actatropica.2016.08.028

3. Gubler DJ. Epidemic dengue / dengue hemorrhagic fever as a public health, social and economic problem in the 21st century. Trends Microbiol [Internet]. 2002; 10 (2): 1003. Available from: https://www.ncbi.nlm.nih.gov/pubmed/11827812 
4. Dickin SK, Schuster-Wallace CJ, SJ Elliott. Mosquitoes and vulnerable spaces: Mapping local knowledge of sites for dengue control in Seremban and Putrajaya Malaysia. Appl geogr. 2015; 46 (2014): 71-9.

5. Gupta N, Srivastava S, Jain A, UC Chaturvedi. Dengue in India-Centenary Review Article. Indian J Med Res [Internet]. 2012; 136 (3): 373-90. Available from: http://www.ijmr.org.in/temp/IndianJMedRes1363373-2582104_071021.pdf

6. Ali SA, Ahmad A. Using analytic hierarchy process with GIS for mapping the risk of dengue in Kolkata Municipal Corporation, West Bengal, India. Spat Korean Soc Inf [Internet]. 2018; 26 (4): 449-69. Available from: https://doi.org/10.1007/s41324-018$0187-\mathrm{x}$

7. Nakhapakorn K, NK Tripathi. An information value based analysis of physical and climatic factors affecting dengue fever and dengue haemorrhagic fever incidence. Int $\mathrm{J}$ Health geogr [Internet]. 2005; 4 (13): 1-13. Available from: https://www.ncbi.nlm.nih.gov/pmc/articles/PMC1177981/\#!po=1.02041

8. Anselin L, brittle E. Spatial statistical analysis and geographic information systems. Ann Reg Sci [Internet]. 1992; 26 (1): 19-33. Available from: https://link.springer.com/article/10.1007/BF01581478

9. Richardson DB, Volkow ND, Kwan MP, Kaplan RM, MF Goodchild, Croyle RT. Spatial Turn in Health Research. Science (80-) [Internet]. 2013; 339 (6126): 1390-2. Available from: https://science.sciencemag.org/content/339/6126/1390

10. Pawattana C, NK Tripathi. Analytical Hierarchical Process (AHP) -based Flood Water Retention Planning in Thailand. GIScience Remote Sens [Internet]. 2008; 45 (3): 34355. Available from: https://www.tandfonline.com/doi/abs/10.2747/1548-1603.45.3.343

11. Vasiljević TZ, Srdjević Z, Bajčetić R, Miloradov MV. GIS and the Analytic Hierarchy Process for Regional Landfill Site Selection in Transitional Countries: A Case Study From Serbia. Environ Manage [Internet]. 2012; 49 (2): 445-58. Available from: https://link.springer.com/article/10.1007/s00267-011-9792-3

12. Hafeez S, Amin M, Ahmed B. Spatial and Spatio-temporal Epidemiology Spatial mapping of temporal risk to improve prevention measures: A case study of the dengue epidemic in Lahore. 2017; 21: 77-85.

13. Wen TH, Lin MH, HJ Teng, Chang NT. Incorporating the human-mosquito Aedes measuring the spatial interactions into urban risk of dengue fever. Appl geogr. 2015; 62: $256-66$

14. H. Zeller, Schuffenecker I. West Nile Virus: An Overview of Its Spread in Europe and the Mediterranean Basin in Contrast to Its Spread in the Americas. Eur J Clin Microbiol Infect Dis [Internet]. 2004; 23 (3): 147-56. Available from: https://link.springer.com/article/10.1007/s10096-003-1085-1

15. Dom NC, Ahmad AH, ZA Latif, Ismail R. Application of GIS-based Analytical Hierarchy Process as a tool for Dengue Risk Assessment. Asian Pacific J Trop Dis. 2016; 6 (12): 930-7. 
16. Chaiphongpachara T, Pimsuka S, Na Ayudhaya WS, Wassanasompong W. The application of geographic information system in dengue haemorrhagic fever risk assessment in samut Songkhram province, Thailand. Int J GEOMATE. 2017; 12 (30): 53-60.

17. Zambrano LI, Rodriguez E, Espinoza-Salvado IA, Fuentes-Barahona IC, Lyra de Oliveira T, Luciano da Veiga G, et al. Spatial distribution of dengue in Honduras during 2016-2019 using a geographic information systems (GIS) -Dengue epidemic implications for public health and travel medicine. Travel Med Infect Dis [Internet]. 2019; 32: 1-10. Available from: https://doi.org/10.1016/j.tmaid.2019.101517 